\title{
CULTURA DIGITAL E A RELAÇÃo PROFESSOR-ALUNO: DA AUTORIDADE PEDAGÓGICA À AUTORIDADE TECNOLÓGICA*
}

Katia Morosov Alonso ${ }^{1}$

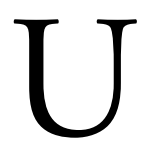

m pouco antes da leitura do livro, o jornal Folha de S.Paulo publicou uma reportagem com dados sobre agressão a professores no estado de São Paulo (PINHO; MARIANI, 2017). Essas agressóes aconteceram em creches, escolas e no ensino superior, tanto público como privado, e em um a cada quatro casos, os alunos foram apontados como os responsáveis pelos ataques. Afirmava a matéria que o número seria muito maior, mas que haveria subnotificação à polícia. Parece que a profissão professor constitui-se, hoje, em profissão de risco, pelo potencial agressivo que se observa na realizaçáo da atividade pedagógica. Para além das agressóes notificadas judicialmente, há outra cujos níveis de violência contra os professores são recorrentes e, talvez, mais numerosos dos que aqui mencionados: o cyberbullying, em tempos de cultura digital que afeta as relaçôes sociais e, especialmente, a pedagógica.

No livro Cyberbullying contra professores: dilemas da autoridade dos educadores na era da concentraçáo dispersa, Antonio Alvaro Soares Zuin, professor na Universidade Federal de São Carlos (UFSCar), vem pesquisando, há algum tempo, sobre o bullying contra professores em redes sociais. Nesse livro, o autor problematiza a relação entre alunos e professores, considerando manifestaçóes veiculadas, mais recentemente, no YouTube.

Com análise sobre vídeos bastante visualizados nesse espaço virtual, o autor chama atenção para o fenômeno crescente do cyberbullying que vitima professores, tratando de situaçóes de agressóes físicas e de constrangimentos entre alunos e eles.

O livro é composto por quatro capítulos e conclusão, cada um deles dedicado a reflexões que convergem para a ideia de que o uso intenso de dispositivos que acessam a internet fragiliza a relação professor-aluno.

\footnotetext{
*Resenha do livro: ZUIN, A.A.S. Cyberbullying contra professores: dilemas da autoridade dos educadores na era da concentração dispersa. São Paulo: Loyola, 2017.

${ }^{1}$ Universidade Federal de Mato Grosso, Programa de Pós-Graduação em Educação - Cuiabá (MT), Brasil.

E-mail: katia.ufmt@gmail.com

DOI: 10.1590/ES0101-73302018187364
} 
Importante destacar que o eixo de análise que o autor propóe se relaciona com a ideia de "autoridade", seja com base na relação pedagógica que se estabelece no cotidiano escolar, seja naquilo que o professor, como "figura moral", instituiria como lugar na escola.

Para fundamentar suas análises, o autor, no primeiro capítulo da obra, apresenta uma discussão sobre as maneiras pelas quais se compreende a autoridade do professor. Com base em Comênio, Rosseau e Herbart, entre os principais pensadores que fundam concepçóes sobre o pedagógico, observa-se que a autoridade do professor se consubstancia mais na e pela relação dele com seus alunos. Assim, se para o "pai" da pedagogia humanista moderna, os professores, mais que transmitir preceitos, deveriam estimular seus alunos a encontrá-los, para um dos "idealizadores" da pedagogia humanista tradicional, o professor seria modelo de autoridade a ser seguido pelos alunos quando das atividades de ensino e aprendizagem. De todo modo, em ambas as concepçóes o professor teria lugar de destaque, considerando sua autoridade pedagógica, quer numa perspectiva de estímulo aos alunos quer como figura moral a pautar a consciência deles.

É evidente que tais concepçôes foram e são criticadas e que a relação professor-aluno é marcada, historicamente, por tensōes, contradições, negações... A autoridade do professor foi e é questionada como toda e qualquer relação de poder. Porém, mais recentemente, com o advento da cultura digital, quando a disjunção espaço e tempo foi superada e a comunicação entre os humanos se fez instantânea, em fluxo e por meio de tecnologias nômades, a sala de aula é, e foi, afetada sobremaneira. Se antes a autoridade do professor estava relacionada à aquisição dos conteúdos escolares, agora, por meio do acesso à rede internet, a informação relativa ao escolar está todo o tempo à disposição do aluno. Questiona-se a função mesma da escola e, por consequência, a autoridade do professor: o "Google", como citado pelo autor, é anedoticamente visto como o "grande professor".

Transcendendo as anedotas e tendo por base o cotidiano escolar, nos capítulos dois e três do livro são analisados vídeos postados e comentados no YouTube. No capítulo dois, os vídeos foram realizados em escolas de Portugal, dos Estados Unidos e da Inglaterra; no capítulo três, em escolas brasileiras. O que haveria de comum em situaçóes que, aparentemente, seriam distintas, considerando os contextos em que foram produzidas? Talvez a resposta náo seja desconhecida: $\mathrm{o}$ uso do celular nas salas de aula.

Por meio da análise dos vídeos, com duração de poucos minutos, são relatadas situaçóes em que alunos, ao serem desprovidos de seus smartphones, entram em "combate" com seus professores para que o aparelho lhes seja devolvido, ou, como ocorrido em dois casos brasileiros, situaçóes em que os professores são ridicularizados justamente pela "quebra" de sua autoridade pedagógica. 
Em cada um dos casos trabalhados pelo autor, e com base em pensadores cuja produção não é específica sobre a cultura digital, denotam-se análises e interpretaçóes que, passando por teóricos como Benjamin, Adorno, Türcke, entre vários outros - com ênfase nestes —, fazem referência à sociedade do espetáculo, ao estar conectado todo o tempo para ser visto e reconhecido, isso como algo comum das convivências na atualidade... Não bastam mais as referências de um espaço e um tempo que fundam existências em si. Agora faz-se necessária a exposição, um lugar no ciberespaço de modo que ali se produzam identidades forjadas em desejo de fruição sardonarcísica, levando a um vício difícil de ser rescindido, já que as redes sociais dele se retroalimentariam. Em determinado momento da leitura fica a impressão de que a obra trata de análises mais "localizadas" nos vídeos; no entanto, sua continuidade revela as implicaçóes do refletir/pensar sobre o deslocamento da autoridade do professor para a autoridade tecnológica. E é nesse contexto que o trabalho pode ser percebido em sua intensidade, apoiando compreensóes que superam o estranhamento causado pelas tecnologias digitais, sobretudo as que convergem no e para o celular, precisamente pela facilidade que se tem em seu manuseio. As telas, como dito pelo autor em referência a Adorno e Simpson, ao produzir os "ferrōes audiovisuais" fascinam os consumidores, exigindo "aguilhôes" cada vez mais poderosos, entendidos como signos da relaçáo passiva que se estabelece entre eles e a indústria cultural.

É, pois, no caldo dessa relação que o deslocamento de uma autoridade pedagógica para a tecnológica tem sua origem, a cultura digital, uma das expressōes atuais da indústria cultural (embora haja discussão apaixonada sobre produção/consumo da informação no contexto da cibercultura), implica busca incessante de estímulos cada vez mais potentes que anestesiam os que foram antes experimentados. $\mathrm{O}$ professor não foge à regra: cada vez mais são compelidos a "aulas shows", como performance.

No capítulo quatro o autor conceitua "concentração dispersa":

O ritmo alucinante das distraçóes que continuamente se alternam, na medida em que nossos olhares são atraídos por estímulos audiovisuais expostos por telas onipresentes, parece estar fazendo que a própria capacidade de concentração seja radicalmente transformada, de tal modo que a dispersão se torna parte de sua constituição (ZUIN, 2017, p. 109).

Sendo assim, questiona-se como trazer de volta à sala de aula a concentração necessária ao estudo que exige esforço e raciocínio... O pretexto da análise dos vídeos supramencionados se descortina; o ciberbullying contra professores tem sua raiz no "desprazer" que a sala de aula representa quando alunos são convidados a se "desconectar", revelando "síndrome de abstinência". Como mencionado pelo autor, Türcke já chamara atenção sobre a dificuldade de concentração como 
um fenômeno cultural intimamente relacionado com a cultura digital. A miríade de informaçóes, telas, aplicativos, páginas, jogos etc., além das muitas funções integradas aos dispositivos tecnológicos, remetem a ideia/ilusão do controle: a concentração seria, ao final, aquilo que o indivíduo escolheria como tal.

Contudo, o autor faz pensar que, contraditoriamente, o professor torna-se cada vez mais essencial quando da universalização da concentração dispersa. Mais que estímulos potentes e frequentes, a ideia de pensar mais amplo, de entendimento do mundo e de elaboração de novos conceitos requer não o convencimento do aluno sobre determinado assunto, e sim que juntos - professores e alunos possam se apropriar das informaçôes, relacioná-las, significá-las e (re)criá-las...

O cyberbullying contra professores seria, portanto, "sintoma" de uma relação fraturada por conta da autoridade cujo lugar tradicional - o da transmissão de conteúdos - já não caberia em tempos de cultura digital. No entanto, para que as aprendizagens escolares se realizem, é fundamental, nesse contexto, reconhecer que os alunos podem e devem contribuir no processo ensino-aprendizagem. Assim, a ação do professor tornar-se-ia maior justamente ao não se ignorar a "voz" dos alunos em meio ao que é produzido em e nas redes comunicacionais, que estruturam a cultura digital.

\section{Referência}

PINHO, A.; MARIANI, D. SP tem quase 2 professores agredidos ao dia: ataque vai de soco a cadeirada. Folha de S.Paulo, Sáo Paulo, 17 set. 2017. Disponível em: <http://wwwl.folha.uol.com.br/paywall/signup.shtml?http://wwwl.folha.uol.com.br/ educacao/2017/09/1919146-sp-tem-quase-2-professores-agredidos-ao-dia-ataque-vai-desoco-a-cadeirada.shtml . Acesso em: 17 set. 2017.

Recebido em 02 de novembro de 2017.

Aceito em 22 de novembro de 2017.

(C) 2018 Centro de Estudos Educação e Sociedade - CEDES Este é um artigo de acesso aberto distribuído nos termos de licença Creative Commons. 